\title{
INTERAÇÕES ESPACIAIS E PROMOÇÃO IMOBILIÁRIA COMO VETORES DA METROPOLIZAÇÃO DO ESPAÇO DE MARITUBA/PA
}

\section{SPATIAL INTERACTION AND REAL STATE DEVELOPMENT AS VECTOR OF METROPOLISATION ABOUT MARITUBA/PA SPACE}

\author{
Willame de Oliveira Ribeiro', José Henrique da Silva Fernandes', \\ 1 Universidade do Estado do Pará (UEPA), Belém, PA, Brasil
}

\author{
Correspondência para: Willame de Oliveira Ribeiro (willame@uepa.br) \\ doi: 10.12957/geouerj.2019.39162 \\ Recebido em: 28 dez. 2018 | Aceito em: 26 ago. 2019
}

\begin{abstract}
RESUMO
Marituba compõe a Região Metropolitana de Belém e vem sendo cada vez mais marcada pelo processo de metropolização, o que se expressa em diversos fatores, entre eles, as interações espaciais e a promoção imobiliária. A problemática a ser aqui desvendada pode ser sintetizada na indagação que se segue: como as interações espaciais entre Marituba e os demais componentes do espaço metropolitano de Belém expressam a metropolização de Marituba e como isso se relaciona com a promoção imobiliária? Mediante o desenvolvimento de procedimentos metodológicos, como construção de referencial teórico, levantamentos documentais e trabalhos de campo, pôde-se constatar importantes transformações no espaço de Marituba e a ampliação da sua conectividade no âmbito do espaço metropolitano. Observou-se ainda que a promoção imobiliária está diretamente relacionada e esse processo, expressando tanto a intensificação das interações espaciais caracterizadoras da condição metropolitana quanto a natureza da metropolização de Belém.
\end{abstract}

Palavras-chave: Interações espaciais; Promoção imobiliária. Metropolização do espaço. espaço metropolitano. Marituba.

\begin{abstract}
Marituba make up the metropolitan region of Belém and have been increasingly noted by metropolisation process, which is express for many factors, between them, the spatial interactions and real state development. The problematic here comes out can be summarized in the followed enquiry: as the spatial interaction between Marituba and others components about belém metropolitan space express the metropolisation of Marituba and how it interact with real state development? Upon acceptance the development about methodological procedure, as theoretical reference building, information gathering and field research, it is evident that important transformations in the Marituba space and expansion of connectivity in context of metropolitan space. It was observed that real state development is still directly associated to this process, expressing as the intensification of spatial interaction characterized about metropolitan condiction as the nature of Belém metropolisation.
\end{abstract}

Keywords: Spatial interaction. Real state development. Metropolisation of space. Metropolitan space. Marituba.

\section{INTRODUÇÃO}

Marituba, oficialmente integrante da Região Metropolitana de Belém, vem apresentando aspectos característicos de um processo de metropolização, entendido aqui como o processo de produção do espaço metropolitano (RIBEIRO, 2017), resultando em uma reorganização de seu espaço urbano. Entendendo as interações espaciais e a promoção imobiliária enquanto elementos fundamentais à caraterização da 
metropolização, a questão cuja resposta se persegue neste artigo está assim definida: Como as interações espaciais entre Marituba e os demais componentes do espaço metropolitano de Belém (Belém, Ananindeua e Benevides) expressam a metropolização de Marituba e como isso se relaciona com a promoção imobiliária?

A busca dessas respostas envolveram procedimentos metodológicos diversos:

Levantamento bibliográfico - voltou-se a melhor compreensão dos conceitos de metropolização do espaço, interações espaciais e promoção imobiliária.

Levantamento documental - Direcionado à formação histórico-territorial do município de Marituba e às interações espaciais entre Marituba e os demais entes do espaço metropolitano de Belém. O Instituto Brasileiro de Geografia e Estatística - IBGE foi a principal fonte para os dados de interações espaciais, reunindo as informações disponibilizadas no censo de 2010, para destacar os dados referentes aos deslocamentos de pessoas por motivo de trabalho e de estudo. A forma como foram analisados e utilizados esses dados será mais bem esclarecida ao longo do texto.

Trabalhos de campo - visando a identificação e a caracterização dos empreendimentos imobiliários, tanto aqueles oriundos da ação do Estado (Programa Minha Casa Minha Vida) ${ }^{1}$ quanto os que resultam da atuação de promotores imobiliários privados, envolvendo levantamento fotográfico e das informações necessárias à composição dos mapas. Além disso, com vistas à qualificação dos dados e da análise, foram realizadas 20 entrevistas com moradores do empreendimento Total Ville Bella Citta - Condomínio Algodoal, pertencente à faixa 3 do Programa Minha Casa Minha Vida, durante o mês de novembro de 2017, por meio de um roteiro semiestruturado com 12 questões.

\footnotetext{
${ }^{1}$ Uma das principais características desse programa é justamente seu profundo atrelamento com a esfera privada, especialmente nas faixas 2 e 3, entretanto, para afeitos desse trabalho, os seus empreendimentos serão considerados como oriundos de políticas públicas, como uma forma de diferenciá-los daqueles empreendimentos resultantes da ação privada e que não contam com nenhuma política habitacional específica para lhe fornecer suporte.
} 
Os resultados desses procedimentos metodológicos estão organizados a seguir em seis seções: a primeira volta-se ao delineamento do referencial teórico e busca apresentar as compreensões aqui adotadas sobre metropolização do espaço e interações espaciais; na segunda seção, é feita a contextualização de Marituba no âmbito do espaço metropolitano de Belém, apresentando, inclusive, um levantamento histórico da constituição do município; em seguida, é apresentado, em linhas gerais, o processo de metropolização de Belém; na quarta seção, são analisadas as interações espaciais entre Marituba e os demais municípios do espaço metropolitano de Belém, mediante os dados de deslocamento temporário de pessoas por motivo de trabalho e de estudo; nas duas últimas seções é enfocada a dinâmica imobiliária de Marituba, buscando relacioná-la às interações espaciais e ao processo de metropolização do espaço.

\section{METROPOLIZAÇÃO DO ESPAÇO E INTERAÇÕES ESPACIAIS}

Para Di Méo (2008) a metropolização, constantemente cria e preserva centralidades, reestruturando os espaços urbanos. Esse processo gera novos usos do espaço e novas paisagens que estão em consonância com as necessidades e aspectos atrelados aos espaços metropolitanos. No entanto, o autor ressalta que a metropolização não deve ser confundida com o processo de urbanização:

[...] a metropolização que não significa urbanização stricto sensu, e nem se confunde totalmente com a globalização (global city de Saskia Sassen), se observa a partir de um nível mínimo de concentrações humanas mais ou menos difusas. Trata-se de um mínimo pouco preciso, o de aglomerações de algumas centenas de milhões de habitantes (se avizinhando a um milhão?) dispostos em torno de um ou de vários centros urbanos... Até constituir conjuntos territoriais agrupando de uma a duas, ou até três dezenas de milhões de indivíduos, dentre os mais expressivos entre eles. (DI MÉO, 2008, p. 2).

Dessa forma, o autor compreende que o espaço metropolitano necessariamente apresenta importância política, econômica, cultural e ideológica que compactuam com as atividades desempenhadas dentro de seu espaço.

Outra autora que se propõe a discutir o processo de metropolização do espaço é Lencioni (2013):

De maneira mais sintética podemos dizer que, em geral, o processo de metropolização imprime características metropolitanas ao espaço, transformando as estruturas pré-existentes, independentemente desses espaços serem ou não metrópoles. Isso significa dizer que o processo 
de metropolização pode incidir sobre espaços metropolitanos ou não [...]. (LENCIONI, 2013, p. $23)$.

Ainda que a visão da autora seja relevante, para os fins da pesquisa optou-se por adotar um posicionamento sobre o processo de metropolização do espaço que está mais associado ao de Di Méo (2008). Compartilhando dessa visão, Ribeiro (2017) considera esses espaços metropolitanos como importantes, mas não como os únicos difusores de modernização, pois isso se configuraria enquanto uma negação da realidade complexa presente na rede urbana. Para o autor, o processo de metropolização deve ser:

[...] entendido basicamente como a produção do espaço metropolitano. Nesse sentido, o resultado do processo de metropolização é a própria metrópole, ou seja, o processo de metropolização se refere ao movimento, às ações que contribuem à constituição do espaço metropolitano. Um movimento que não cessa quando a metrópole ganha existência, mas que a acompanha em seu constante processo de produção. (RIBEIRO, 2017, p. 155).

Dessa forma, a própria metrópole se reproduz através da metropolização do espaço. Di Méo (2008) entende o papel da metrópole nessa perspectiva da seguinte forma:

\footnotetext{
Na palavra "metrópole", sabe-se contem "póle" certamente, poli, a cidade, mas também "pólo" (latim polus e grego polos), quer dizer o pivô sobre o qual gira uma coisa, um centro e um eixo em torno do qual se desenvolve uma dinâmica, um movimento; não são os pólos os dois pontos virtuais pelos quais passa o eixo de rotação da Terra? Mas o "pólo" é também um ponto que atrai (pólo de atração) em um dado campo magnético, metáfora possível de um espaço geográfico e social submisso às leis físicas. Se ele atrai, é porque ele irradia, exerce influência sobre seu meio ambiente. Esta atração descreve no espaço um gradiente; ela se atenua com a distância se ela não é reativada por polarizações secundárias, por retransmissões do pólo ou metrópole. À medida que a influência do pólo se esgota ou se reanima com a distância, ela engendra jogos de escala que fundam novas unidades geográficas. (DI MÉO, 2008, p. 06).
}

Sendo assim, é notório o papel desempenhado pelas metrópoles no seu processo de dinamização e participação na estruturação da rede urbana, uma vez que as mesmas possuem grande capacidade de atração e difusão de fluxos, sejam materiais ou informacionais.

Ao se discutir o fenômeno da metropolização do espaço é necessário compreender que o espaço metropolitano é dotado de complexidade, ou seja, é dotado de diversos processos que ocorrem de forma simultânea dando características particulares ao espaço. Ao se pensar o processo de constituição de uma metrópole é indispensável a ideia de conectividade que se constrói sob as diferentes partes desse recorte espacial. 
Dentro das metrópoles nada expressa melhor a ideia de conectividade do que o conceito de interações espaciais, que podem ser vistas enquanto um conjunto de fluxos das mais diferentes naturezas: informações, pessoas, mercadoria e capital. Logo, ao se trabalhar com a metropolização do espaço é necessário identificar de que forma esses fluxos se apresentam e como os mesmos expõem relevância para o processo.

No mundo atual, nas palavras de Catelan (2012), as interações espaciais ganham força enquanto perspectiva de análise, “[...] porque as instituições, os agentes, as pessoas e tudo o que produz espaço está de fato ou potencialmente conectado em redes". (p. 35).

Ullman (1980) entende as interações espaciais como o verdadeiro objeto de estudo da geografia. Apesar de se referir mais diretamente aos deslocamentos de mercadorias e pessoas, a concepção de Ullman poddui grande relevância, dando ênfase ao papel da distância para compreender a intensidade das interações realizadas entre áreas distintas.

Na literatura mais recente, Corrêa (1997) assim define o conceito em questão:

As interações espaciais constituem um amplo e complexo conjunto de deslocamentos de pessoas, mercadorias, capital e informação sobre o espaço geográfico. Podem apresentar maior ou menor intensidade, variar segundo a frequência de ocorrência e, conforme a distância e direção, caracterizar-se por diversos propósitos e se realizar através de diversos meios e velocidades. (CORRÊA, 1997, p. 279).

Corrêa (1997) entende que as interações espaciais devem ser vistas como parte essencial do processo de transformação social, ou seja, não podem ser consideradas apenas como fluxos que se realizam sob o espaço, mas como parte integrante do mesmo. Para o autor, as interações espaciais concebidas no sistema capitalista apresentaram impactos na sociedade reproduzindo diferenças e alterando a maneira pela qual as interações se apresentavam na sociedade. As interações realizadas entre cidades tornaramse cada vez mais heterogêneas e com maior frequência, ignorando o fator distância, possibilitando a ultrapassagem de um determinismo no fator distância e em um número reduzido de interações entre poucos centros. 
Dentro do espaço metropolitano é possível destacar o papel das interações ao se discutir a ideia de conectividade ou mobilidade, pois é através destes que é constituído o cotidiano dos indivíduos, no tráfego de carros, ônibus, no próprio deslocamento de pessoas por motivos de trabalho e estudo. Além da difusão de informações e mercadorias. No entanto, na mobilidade de pessoas é que se constitui o espaço do indivíduo, que se reforçam as centralidades e os fluxos, dando forma ao processo que constitui a metrópole.

\section{Marituba no contexto do espaço metropolitano de Belém}

Após refletir sobre os componentes teóricos pertinentes à discussão levantada nesta pesquisa, é necessário adentrar no lócus geográfico da investigação. Logo, este tópico trata do processo de constituição de Marituba/PA, sua dinâmica urbana e analisa a sua inserção na realidade metropolitana de Belém.

A origem de Marituba, segundo Nunes (2012), data de 1800 com o estabelecimento de algumas famílias na área que atualmente compreende o município. Essas famílias viviam basicamente da agricultura familiar. Em 1871, por meio da Lei Provincial nำ 676, de setembro do mesmo ano, foram disponibilizadas seis léguas de terra localizadas na Estrada de Bragança, para atender às necessidades do Serviço de Colonização do Pará, determinando a criação de diversos núcleos para este fim. Por volta de 1873, as terras foram concedidas, porém sua efetiva colonização só ocorreu em meados de 1875, quando chegaram os primeiros colonos que ocuparam os lotes demarcados. A área ocupada por estes ficou conhecida como Colônia Agrícola de Benevides. Essa Colônia deu início à intensiva marcha de povoamento da Zona Bragantina. ${ }^{2}$

A política de povoamento nesta região foi essencial, pois quando se deu início à construção da Estrada de Ferro de Bragança - EFB, a Colônia de Benevides já havia completado oito anos. Dessa forma, o

\footnotetext{
${ }^{2}$ Corresponde à área do Nordeste Paraense entre Belém e Bragança, objeto de importantes políticas de colonização entre o final do século XIX e o início do século XX e que correspondeu ao percurso da Estrada de Ferro de Bragança - EFB, construída entre 1883 e 1908 e que deixou de funcionar em 1965. A esse respeito ver Penteado (1967), Égler (1961), Ribeiro (2017) e Leandro \& Silva (2012).
} 
estabelecimento de colônias agrícolas acabou por compactuar com a construção da estrada de ferro, uma vez que era necessário construir diversas paradas ao longo da construção. É diante deste cenário, que surge de forma primária o povoado de Marituba, pois, na medida em que os trilhos foram sendo fixados, novos povoados foram surgindo.

De acordo com Nascimento (2013), em 1905, o governador Augusto Montenegro estabeleceu a necessidade de se formarem diversas oficinas da Estrada de Ferro. Porém, ao passo que essas foram sendo construídas, também houve a necessidade de se construir vilas que abrigassem os operários, a fim de fixá-los nas proximidades das oficinas. É diante desta necessidade, que, em 1906, é fundada a Vila Operária, que posteriormente daria origem a Vila de Marituba.

Outro aspecto que se torna relevante mencionar é o início da construção em 1937 e a instalação da Colônia de Marituba, em 1941. A instalação tinha por finalidade atender pessoas que eram acometidas por hanseníase. Segundo Fonseca (2007), a hanseníase era considerada um dos mais graves problemas de saúde do Brasil, com níveis alarmantes no Pará. O tratamento determinado pelo governo na época era o total isolamento dos doentes, o que acabou gerando problemas sociais dos mais variados.

A construção da Colônia se deu afastada do centro de Marituba e por muito tempo fez com que o município tivesse desenvolvido uma imagem negativa, o que perdurou até que estudos mais avançados sobre a doença mostrassem que determinadas medidas e posturas estavam equivocadas em relação ao tratamento da doença. Após esses avanços a área da Colônia foi dividida administrativamente e deu origem a diversos bairros que atualmente fazem parte do município de Marituba.

A área que atualmente pertence à Marituba por muito tempo foi motivo de disputas, uma vez que até 1943, quando foi criado o município de Ananindeua, a área de Marituba fazia parte de Belém, porém, após essa criação, passou a fazer parte de Ananindeua. Até que em 1961 passou a pertencer a Benevides, após o reconhecimento de Benevides enquanto município. 
No entanto, ao passo que Marituba foi crescendo também cresceu a demanda por serviços que atendessem às necessidades locais, reforçando os discursos e reivindicações por autonomia. Dessa forma, através da Lei $n^{0} 5.857$, de 22 de setembro de 1994, foi criado o município de Marituba, sendo este desmembrado do município de Benevides. (Figura 1).

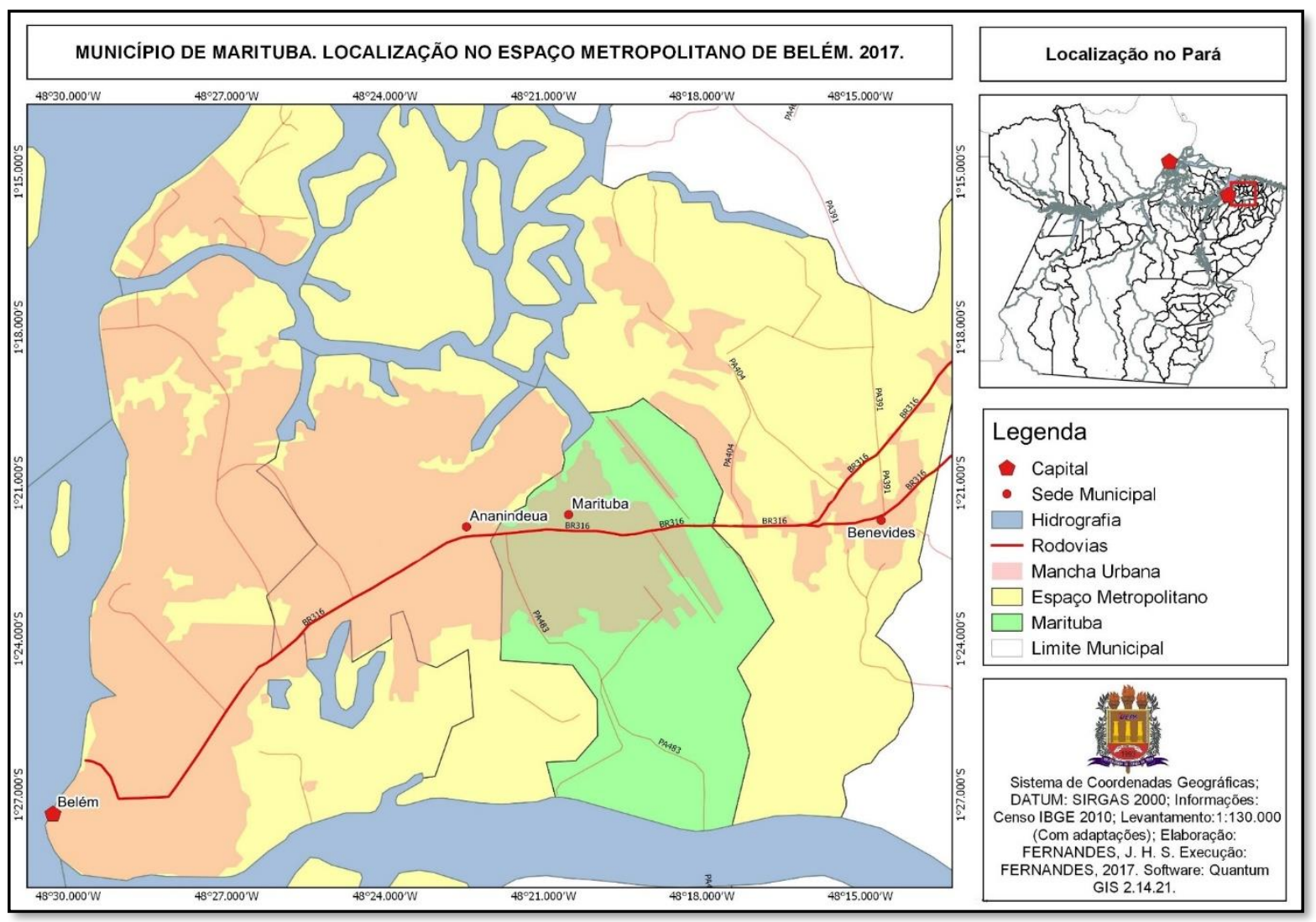

Figura 1. Município de Marituba. Localização no espaço metropolitano de Belém. 2018. Fonte: Elaboração própria. Organização: Fernandes, 2018.

Atualmente, Marituba é um dos municípios da RMB que mantém maiores interações com Belém, sendo estas bem diversificadas. No entanto, a fim de compreender de que forma essas relações se apresentam e como a cidade está inclusa na realidade metropolitana, cabe realizar antes uma reflexão sobre o processo de metropolização de Belém, para que seja possível adentrar nas características desse espaço metropolitano e como o mesmo vem se produzindo em Marituba.

\section{O processo de metropolização de Belém}


Por volta dos anos 1960 já é possível reconhecer características metropolitanas em Belém, com "a incorporação de cidades, vilas e povoados próximos [...], definindo uma malha urbana única, ainda que fragmentada”. (TRINDADE JÚNIOR, 2016, p. 22). Nos anos 1980, o processo de metropolização de Belém já está num segundo momento, assumindo, de acordo com Trindade Júnior (2016), uma forma dispersa.

Um dos aspectos desse segundo momento foi o intenso processo de deslocamento da população com baixo poder aquisitivo para áreas distantes do centro da cidade e daquelas de maior valorização, com destaque para locais ao longo da BR-316 e da Rodovia Augusto Montenegro. A partir disso a malha urbana se espraiou "[...] estabelecendo o processo de conurbação não só com os núcleos de Ananindeua e Marituba, como também com a Vila de Icoaraci e a Ilha de Caratateua [...]". (TRINDADE JÚNIOR, 2016, p. $125)$.

Segundo o autor, esse processo de relocalização da população ocorreu de duas formas: uma maneira direta e outra indireta. A primeira refere-se às ações urbanísticas do poder público que se utilizava do pretexto de realocar a população em outras áreas, mediante a necessidade de realizar obras no local de intervenção, como é muito bem discutido e analisado por Abelém (1989); a segunda está atrelada à ação imobiliária, ligada à especulação e à valorização das áreas ocupadas pela população mais pobre, resultando em uma maior cobrança de impostos, impossibilitando que os mesmos continuem ali, logo acabam por vender ou abandonar seus imóveis em busca de moradias mais acessíveis.

Essa política de remanejamento da população de camadas sociais mais baixas para a Área de Expansão Metropolitana resultou em um adensamento populacional que colaborou com o processo de ocupação nessas localidades, dando características de uma forma metropolitana dispersa, através da oferta de habitações, seja por meio do Estado, capital imobiliário ou pela ocupação espontânea.

No período de crescimento da área metropolitana são destacados dois vetores pelos quais a expansão ocorre: o eixo Belém-Benevides, perpassando por Marituba, e o eixo Belém-Icoaraci. O primeiro foi caracterizado pela intensa atuação da política habitacional do Estado, a partir da grande oferta de terras 
com valor reduzido, especialmente a partir de Ananindeua. Já o segundo teve maior atuação do capital imobiliário privado voltado para a construção de habitações populares. A presença de ambos os vetores revela a forma dispersa do processo de metropolização mais consolidado.

No ano de 1995 foi instituída pela Lei Complementar nº 027, de 19 de outubro, a Região Metropolitana de Belém, com os seguintes municípios: Belém, Ananindeua, Benevides, Marituba e Santa Bárbara do Pará (DIÁRIO OFICIAL DO ESTADO DO PARÁ, n. 28.116, de 22/12/95). Posteriormente, através da Lei Complementar n⿳ํㅜ 072, de 20 de Abril de 2010, publicada no Diário Oficial do Estado nº 31.656, de 30 de Abril de 2010, foi inserido outro município à Região Metropolitana de Belém, Santa Izabel do Pará. E através da Lei Complementar n. 076, de 28 de dezembro de 2011, (DIÁRIO OFICIAL DO ESTADO DO PARÁ, 28 DE DEZEMBRO DE 2011, CADERNO 2, p. 8) foi inserido também o município de Castanhal. (Figura 2).

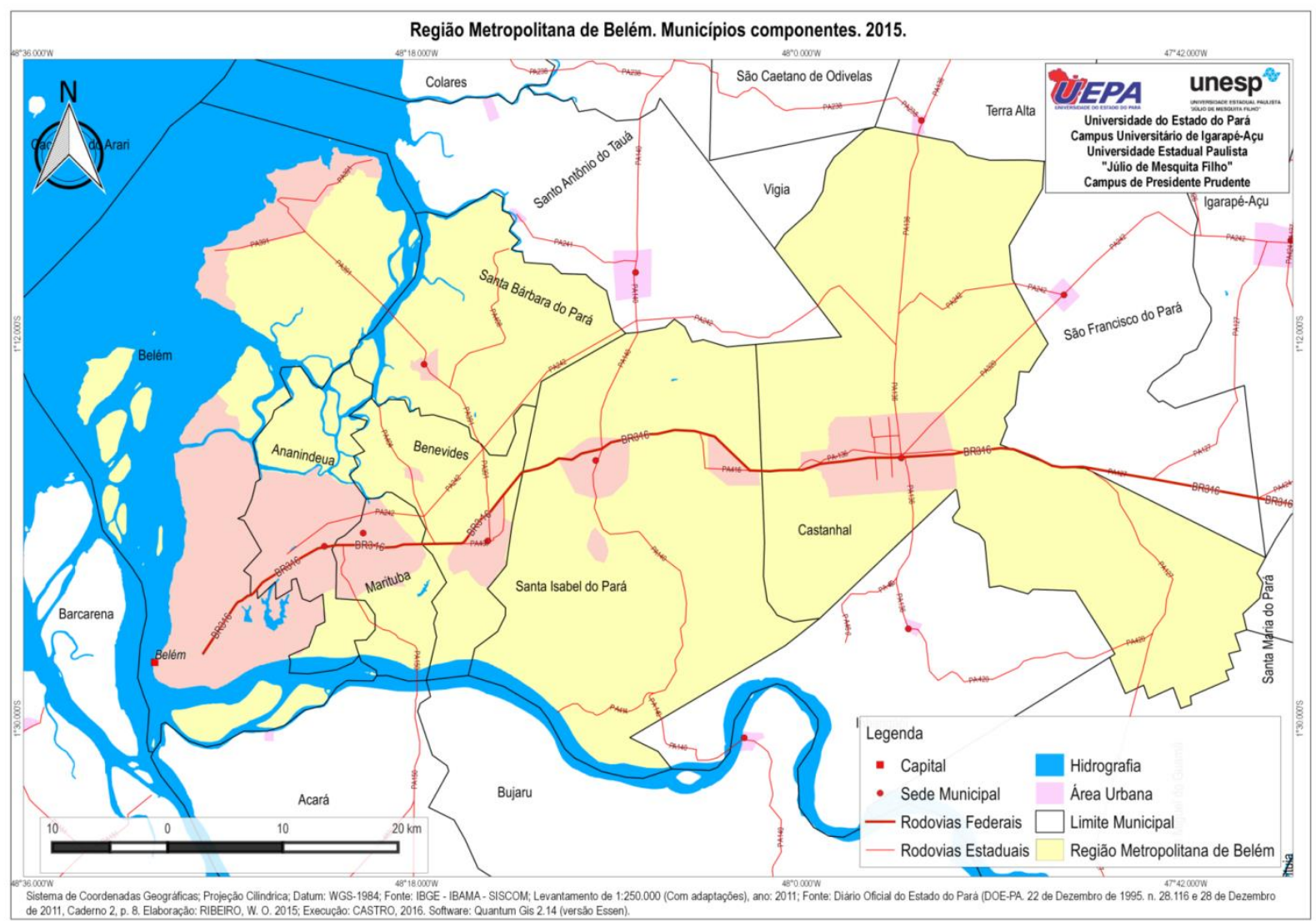

Figura 2. Região Metropolitana de Belém. Municípios Componentes. 2015. Fonte: Ribeiro (2017). 
Dessa maneira, atualmente a Região Metropolitana de Belém tem como municípios componentes Belém, Ananindeua, Marituba, Benevides, Santa Bárbara do Pará, Santa Izabel do Pará e Castanhal.

A produção do espaço metropolitano de Belém foi marcada pela atuação de diversos agentes ligados à construção de habitações de diferentes camadas da sociedade. Os espaços localizados na área central foram alvo, mais intensamente, de disputas entre a faixa da população mais pobre, promotores imobiliários e o próprio Estado até a década de 1980. Desde então, a metrópole belenense adquiriu um caráter de expansão dispersa, acompanhando o desenvolvimento de novas fronteiras econômicoimobiliárias que tendem a ditar os caminhos do desenvolvimento da metrópole.

A partir dessa nova configuração espacial foi-se redesenhando a área de expansão metropolitana, em especial para esta pesquisa, a área presente no eixo Belém-Benevides, o qual apresenta grande disposição de serviços e um alto desenvolvimento e emprego do capital imobiliário para produzir moradias para a população de baixa renda que fora excluída da área central metrópole e também para aquela parte da população com alto poder aquisitivo que tende a buscar condomínios fechados longe do núcleo metropolitano.

Contextualizado o processo de metropolização de Belém cabe agora refletir sobre a maneira como o município de Marituba passou a fazer parte do contexto metropolitano. Para tanto, serão considerados aspectos referentes às interações espaciais que caracterizam a realidade metropolitana.

\section{As interações espaciais como expressão do processo de metropolização de Marituba}

Marituba passou a fazer parte da Região Metropolitana de Belém no ano de 1995. No entanto, apenas a institucionalização de uma RM muitas vezes não corresponde à realidade daquela configuração espacial. Por isso, estudos como o de Ribeiro (2009) buscam compreender essas configurações e diferenciam o grau de densidade e conectividade entre os espaços pretensamente metropolitanos. 
Logo, a partir da discussão realizada sobre o processo de metropolização de Belém, cabe agora ressaltar de que maneira Marituba passa a fazer parte da realidade metropolitana. Para tanto, é necessário compreender como o processo de metropolização alcançou a cidade de Marituba e como o mesmo se apresenta nela.

Como ressaltado anteriormente, o processo de metropolização de Belém foi configurado a partir de dois eixos de expansão: Belém-Benevides e Belém-Icoaraci. O eixo Belém-Benevides configurou-se enquanto uma área de expansão de moradias populares. Veloso (2017) chama a atenção para o fato da estruturação dessa metrópole apresentar uma alta concentração de população de alta renda no centro metropolitano ao passo em que e o espraiamento da malha urbana ocorre com a ampla periferização das camadas mais pobres da sociedade.

Para o autor, um dos vetores de expansão, a rodovia BR-316, com direção aos municípios periféricos da RMB, vem crescendo a partir dessa periferização das classes baixas e médias da sociedade, uma vez que estas saem do centro metropolitano em direção a outros municípios como Ananindeua, Marituba e Benevides.

Esse tipo de movimento está relacionado à atuação dos agentes produtores do espaço urbano:

A periferização metropolitana, principal elemento constituinte do vetor da BR-316, deu-se de forma estimulada pelo Estado, por exemplo, na política de habitação, através de suas Companhias de Habitação e construção de grandes conjuntos habitacionais. (VELOSO, 2017, p. 876).

$\mathrm{Na}$ atualidade, mediante a atuação do Estado na oferta de habitações populares longe do núcleo metropolitano, é possível notar que é reforçada a atuação desse agente no sentido do direcionamento das camadas mais baixas para outros municípios da região metropolitana. Esse movimento reforça o caráter da produção do espaço metropolitano já estabelecido desde os anos 1980, uma vez que o direcionamento dessas camadas é novamente voltado à periferia, no caso, os outros municípios da RMB, a fim de direcionar investimentos mínimos de infraestrutura para reforçar o processo na área em questão. 
A produção da malha metropolitana de Belém, portanto, evidencia-se por meio dos fluxos entre os municípios, do assentamento de pessoas de baixa renda e da crescente demanda por serviços e infraestrutura básica. Essa malha descontínua, porém reafirmada por esses fatores, é uma das principais características da Região Metropolitana de Belém.

Para Veloso (2017) a periferização ajudou a configurar a malha metropolitana de Belém, a partir da tendência de ocupação das áreas mais afastadas do núcleo metropolitano pela população de baixa renda. Ao refletir sobre o posicionamento do autor, é perceptível que ao longo dos últimos anos, políticas habitacionais vêm adquirindo esse caráter periférico de produção de empreendimentos imobiliários e, posteriormente, o Estado vem e oferece serviços necessários à população da localidade.

No entanto, o desenvolvimento de um espaço metropolitano vai além apenas da presença de habitações. Ribeiro (2017) entende que dentro do recorte oficial da Região Metropolitana de Belém, existe um espaço metropolitano que é composto pelos municípios que possuem mais características metropolitanas, e são dotados de maior conectividade e complexidade em seu espaço, sendo estes, Belém, Ananindeua, Marituba e Benevides. Apesar do reconhecimento dos municípios de Santa Bárbara, Santa Izabel e Castanhal como componentes da Região Metropolitana de Belém ser oficial, na perspectiva de um espaço metropolitano, a caracterização desses enquanto metropolitanos ainda é questionável.

Tais questionamentos surgem ao passo que se analisa o quadro dos municípios mediante uma verificação das interações que os mesmos estabelecem entre si. As interações espaciais são parte essencial do processo de metropolização, portanto, a fim de responder os questionamentos levantados neste trabalho, cabe refletir de que maneira o município de Marituba está incorporado na realidade metropolitana de Belém a partir da intensidade das interações que são estabelecidas entre os municípios do espaço metropolitano. 
O foco aqui se dá nas interações espaciais que dizem respeito ao espaço metropolitano ${ }^{3}$, tendo por centro da análise o município de Marituba, apesar disso são apresentados dados relativos a todos os municípios oficiamente integrantes da RMB. Apoiado nesse conjunto de informações, que caracteriza 0 deslocamento de pessoas por motivos de trabalho e de estudo, é possível analisar a complexidade desse espaço metropolitano e a intensidade das interações que o constituem.

\section{Deslocamentos por trabalho}

A análise dos deslocamentos temporários de pessoas por motivo de trabalho foi possível através dos dados do censo demográfico brasileiro de 2010 (IBGE, 2010). Leva-se em conta o número de trabalhadores que, em 2010, se deslocavam para outros municípios para dedicar-se a atividades remuneradas. Os dados levam em consideração as interações diárias, semanais e mensais, entre 0 município no qual o indivíduo trabalha e o de moradia. Além dos dados do IBGE, para o desenvolvimento do cálculo de intensidade dos deslocamentos, será realizado o mesmo procedimento elaborado por Ribeiro (2017), no qual é calculada a intensidade dos deslocamentos por meio da razão entre o número de indivíduos que realizou o deslocamento e a população total do município de origem.

Inicialmente, serão analisados os deslocamentos para Belém a partir dos municípios que compõem o espaço metropolitano. No entanto, a fim de ratificar as observações de Ribeiro (2017), optou-se por demonstrar as interações dos municípios da região metropolitana como um todo. Dessa forma, será possível compreender as interações dos municípios de Ananindeua, Benevides e Marituba com Belém, evidenciando como os mesmos apresentam maior conectividade com o núcleo metropolitano que os demais formadores da RMB, Castanhal, Santa Bárbara do Pará e Santa Izabel do Pará.

\footnotetext{
${ }^{3}$ Nesta pesquisa, compreende-se o espaço metropolitano de Belém como a área que abrange os municípios de Belém, Ananindeua, Marituba e Benevides. Como ressaltado por Ribeiro (2017), esses municípios apresentam maior dinâmica metropolitana dentre os municípios da RMB. Os demais, embora estejam institucionalizados enquanto componentes da região metropolitana, não possuem as mesmas características de conectividade e densidade próprias de um espaço metropolitano; logo seu reconhecimento enquanto tal é questionável.
} 
A Tabela 1 apresenta os deslocamentos motivados por trabalho que tinham como destino Belém e origem os municípios da RMB, no ano de 2010. A Fim de compreender a intensidade desses fluxos, foi gerado um indicador, Índice de Intensidade do Deslocamento Temporário por Trabalho - IIDTT, com base no procedimento desenvolvido por Ribeiro (2017).

\begin{tabular}{lcccc}
\hline & & POPUlAÇÃo DE & N. DE PESSOAS QUE \\
ORIGEM & SE DESLOCAVAM & IIDTT** \\
\hline 1 & Ananindeua & 471.980 & 65.621 & 139,0 \\
2 & Marituba & 108.246 & 10.879 & 100,5 \\
3 & Benevides & 51.651 & 3.827 & 74,0 \\
4 & Santa Bárbara Do Pará & 17.141 & 761 & 44 \\
5 & Santa Izabel Do Pará & 59.466 & 1193 & 20 \\
6 & Castanhal & 173.149 & 1139 & 8 \\
\hline
\end{tabular}

Tabela 1. Região Metropolitana de Belém. Deslocamentos temporários de pessoas por motivo de trabalho com destino Belém/PA. 2010 Fonte: IBGE (2010); Ribeiro (2017).

\footnotetext{
*Como já assinalado, foram considerados os municipios do espaço metropolitano e os demais da RMB, evidenciando que os primeiros apresentam maior conectividade e densidade com Belém, correspondendo, de fato, a um espaço metropolitano. ** Índice de Intensidade de Deslocamento Temporário por Trabalho - determinado pela divisão do número de pessoas que realizaram o deslocamento pela população total do município em 2010, multiplicado por 1000 .
}

Fonte: IBGE (2010); Ribeiro (2017).

Ao analisar a Tabela 1 é possível verificar que os municípios de Ananindeua, Marituba e Benevides apresentam maior quantidade de indivíduos que se deslocam e também maior intensidade desses fluxos para Belém, do que os demais municípios. O primeiro apresenta 65.621 indivíduos que fazem esse deslocamento e o índice de Intensidade do Deslocamento Temporário por Trabalho - IIDTT é de 139, o segundo 10.879 indivíduos e 100,5 de IIDTT, o terceiro 3.827 indivíduos e 74 de IIDTT.

A intensidade das interações apresentadas na Tabela 1 evidencia que os munícipios componentes do espaço metropolitano de Belém tem um grau de conectividade mais intenso do que os demais da Região Metropolitana de Belém. A intensidade dos deslocamentos a partir de Ananindeua é reflexo do seu alto grau de articulação com Belém e, por conseguinte, da materialização substancial do processo de metropolização em seu espaço, expresso, por exemplo, na grande quantidade de linhas de ônibus e numa maior facilidade de locomoção de indivíduos para o núcleo metropolitano em busca de trabalho. 
Tal perspectiva evidencia que o processo de metropolização do espaço está razoavelmente atuante ainda em Benevides, não demonstrando grande relevância na produção do espaço dos componentes da RMB não relacionados entre os integrantes do espaço metropolitano.

A partir do apresentado, para atender aos propósitos dessa pesquisa, cabe agora expor as interações espaciais referentes somente ao espaço metropolitano em dois pontos: o primeiro mostrando os deslocamentos provenientes dos munícipios desse espaço para Marituba; e o segundo evidenciando os deslocamentos de Marituba para esses outros municípios. Dessa forma, a partir da compreensão desses dados, busca-se esclarecer de que maneira o município de Marituba está inserido na realidade metropolitana e sua relação com os demais entes desse espaço.

A Tabela 2 apresenta os deslocamentos por trabalho dos municípios desse espaço metropolitano para Marituba, no ano de 2010. É possível notar que dentre os entes do espaço metropolitano, os fluxos se diferenciam bastante. É evidente que a importância de Marituba no que se refere a deslocamentos por trabalho é muito maior para Ananindeua que apresenta 4,87 de IIDTT e Benevides 9,21 de IIDTT do que para Belém com apenas 0,90 IIDTT. A proximidade de Marituba para Ananindeua e Benevides é um fator decisivo para esse quadro. No entanto, os deslocamentos em menor intensidade de Belém para Marituba exemplificam o grau de concentração de ofertas de trabalho e serviços dentro do núcleo metropolitano e em menor escala nos outros entes desse espaço.

\begin{tabular}{cccc}
\hline MUNICIPIO DE ORIGEM & $\begin{array}{c}\text { POPULAÇÃO DE } \\
\text { ORIGEM }\end{array}$ & $\begin{array}{c}\text { N. DE PESSOAS QUE SE } \\
\text { DESLOCAVAM }\end{array}$ & IIDTT* \\
\hline Ananindeua & 471.980 & 2.300 & 4.87 \\
Belém & 1.393 .399 & 1.256 & 0.90 \\
Benevides & 51.651 & 476 & 9.21 \\
\hline
\end{tabular}

Tabela 2. Marituba. Deslocamentos temporários de pessoas por motivo de trabalho com origem no espaço metropolitano de Belém. 2010 Fonte: IBGE (2010); Ribeiro (2017).

*Indice de Intensidade de Deslocamento Temporário por Trabalho - determinado pela divisão do número de pessoas que realizaram o deslocamento pela população total do município de origem em 2010, multiplicado por 1000. 
Nessa perspectiva, é possível identificar também que Marituba apresenta uma quantidade relativa de empregos que atendem aos moradores dos seus municípios vizinhos, embora não na mesma proporção que Belém. O município de Benevides apresenta maior intensidade no IIDTT para Marituba, uma vez estando mais distante do núcleo metropolitano que os outros dois municípios.

É importante também analisar os deslocamentos que partem de Marituba para o espaço metropolitano como um todo. A Tabela 3 demonstra os deslocamentos por trabalho que tiveram Marituba como origem e os municípios de Belém, Ananindeua e Benevides como destino. Considerando esses deslocamentos, é possível destacar que o movimento para Belém apresenta-se superior ao existente para os outros dois municípios, ainda de acordo com a concentração de atividades e serviços no núcleo metropolitano. Em seguida vem Ananindeua, por também possuir maior presença de atividades e serviços em seu espaço e, por fim, Benevides que diferentemente dos outros dois, ainda não conta com essa diversificação de postos de trabalho

\begin{tabular}{|c|c|c|c|c|c|c|c|}
\hline \multirow[t]{3}{*}{ ORIGEM } & \multirow{3}{*}{$\begin{array}{l}\text { POPUL. } \\
\text { MUNIC. } \\
\text { ORIGEM }\end{array}$} & \multicolumn{6}{|c|}{ DESTINO } \\
\hline & & \multicolumn{2}{|c|}{ Belém } & \multicolumn{2}{|c|}{ Ananindeua } & \multicolumn{2}{|l|}{ Benevides } \\
\hline & & $\begin{array}{c}\text { N. DE } \\
\text { PESSOAS }\end{array}$ & IIDTT* & $\begin{array}{c}\text { N. DE } \\
\text { PESSOAS }\end{array}$ & $\begin{array}{c}\text { IIDT } \\
\mathrm{T}\end{array}$ & $\begin{array}{c}\text { N. DE } \\
\text { PESSOAS }\end{array}$ & IIDTT \\
\hline Marituba & 108.246 & 10.879 & 100,5 & 3.305 & 30,5 & 276 & 2,5 \\
\hline
\end{tabular}

Tabela 3. Espaço metropolitano de Belém. Deslocamentos temporários de pessoas por motivo de trabalho com origem em Marituba. 2010Fonte: IBGE (2010); Ribeiro (2017).

\footnotetext{
*Indice de Intensidade de Deslocamento Temporário por Trabalho - determinado pela divisão do número de pessoas que realizaram o deslocamento pela população total do município de origem em 2010, multiplicado por 1000.
}

Diante dos dados apresentados, é possível concluir que no que se refere à intensidade de fluxos de deslocamentos por trabalho no espaço metropolitano de Belém, o núcleo metropolitano ainda se configura enquanto o grande espaço de concentração de atividades e de serviços. Ananindeua, Marituba e Benevides se configuram enquanto fortes emissores de população que busca essas atividades em Belém. 
No que se refere à ideia de conectividade que se apresentou para se reconhecer o espaço metropolitano, é perceptível que Marituba apresenta fluxos bem relevantes e intensos com os demais entes desse espaço. O município já possui capacidade de atender, em menor escala, uma parte da demanda de Benevides, e quando se analisam os deslocamentos da população local em direção a Belém, é notável a intensidade do IIDTT, próxima a de Ananindeua, bem mais articulado com o núcleo metropolitano

\section{Deslocamentos por estudo}

Assim como no item anterior, a análise dos deslocamentos de pessoas por motivo de estudo foi realizada mediante os dados do censo de demográfico brasileiro de 2010 (IBGE, 2010) e de acordo também com o procedimento desenvolvido por Ribeiro (2017), pelo qual se obtém a intensidade dos deslocamentos a partir da razão entre o número de indivíduos que realizou o deslocamento e a população total do município de origem. Dessa maneira, é possível entender a situação das pessoas que estudavam em um município diferente daquele em que residiam, levando em consideração as interações diárias, semanais e mensais.

Seguindo a organização do item anterior, primeiramente serão compreendidos os deslocamentos de pessoas para Belém, tendo como recorte espacial a ser analisado nesta pesquisa, o espaço metropolitano. No entanto, também serão expostos os dados referentes à região metropolitana como um todo, para diferenciar o grau de intensidade desses fluxos e evidenciar a conectividade característica do espaço metropolitano.

De acordo com o exposto na Tabela 4, os deslocamentos temporários por estudo apresentam-se bem mais intensos a partir dos municípios que fazem parte do espaço metropolitano de Belém. Ananindeua apresenta o maior IIDTE para Belém, com 48,2, seguido por Benevides, com 22,4 e, por último, Marituba com 21,6. Essa configuração reforça a ideia de densidade e conectividade mais atrelada ao que se entende como espaço metropolitano, do que para os outros componentes da Região Metropolitana de Belém. 


\begin{tabular}{cccc}
\hline MUNICIPIO DE ORIGEM* & $\begin{array}{c}\text { POPULAÇÃO DE } \\
\text { ORIGEM }\end{array}$ & $\begin{array}{c}\text { N. DE PESSOAS QUE } \\
\text { SE DESLOCAVAM }\end{array}$ & IIDTE** $^{* *}$ \\
\hline Ananindeua & 471.980 & 22.745 & 48,2 \\
Benevides & 51.651 & 1156 & 22,4 \\
Marituba & 108.246 & 2235 & 21,6 \\
Santa Barbara Do Pará & 17.141 & 166 & 9,6 \\
Santa Izabel Do Pará & 59.466 & 470 & 8 \\
Castanhal & 173.149 & 1130 & 7 \\
\hline
\end{tabular}

Tabela 4. Região Metropolitana de Belém. Deslocamentos temporários de pessoas por motivo de estudo com destino a Belém/PA. 2010Fonte: IBGE (2010); Ribeiro (2017).

\footnotetext{
** Assim como na Tabela 1, foram considerados os munícipios do espaço metropolitano e os demais da RMB, evidenciando que os primeiros (verde mais escuro) apresentam maior conectividade e densidade, correspondendo de fato a um espaço metropolitano.

** Índice de Intensidade de Deslocamento Temporário por Estudo - determinado pela divisão do número de pessoas que realizaram o deslocamento pela população total do município de origem em 2010, multiplicado por 1000.
}

É importante também compreender, para os fins desta pesquisa, os deslocamentos com origem nos municípios do espaço metropolitano e destino em Marituba, a fim de entender a inserção do mesmo na realidade metropolitana (Tabela 5).

\begin{tabular}{cccc}
\hline MUNICIPIO DE ORIGEM & $\begin{array}{c}\text { POPULAÇÃO DE } \\
\text { ORIGEM }\end{array}$ & $\begin{array}{c}\text { N. DE PESSOAS QUE } \\
\text { SE DESLOCAVAM }\end{array}$ & IIDTE* \\
\hline Ananindeua & 471.980 & 431 & 0,91 \\
Belém & 1.393 .399 & 170 & 0.12 \\
Benevides & 51.651 & 278 & 5,3 \\
\hline
\end{tabular}

Tabela 5. Marituba. Deslocamentos temporários de pessoas por motivo de estudo com origem no espaço metropolitano de Belém. 2010 Fonte: IBGE (2010); Ribeiro (2017).

*Índice de Intensidade de Deslocamento Temporário por Estudo - determinado pela divisão do número de pessoas que realizaram o deslocamento pela população total do município de origem em 2010, multiplicado por 1000.

Fonte: IBGE (2010); Ribeiro (2017).

É notório que Benevides aparece com um IIDTE bem superior aos outros municípios, o que obedece a maior distância do núcleo metropolitano e maior proximidade para com Marituba. No caso de Ananindeua e Belém, por já se apresentarem enquanto dois centros polarizadores de deslocamentos por estudo, o IIDTE para Marituba é menor, visto que ambos conseguem suprir grande parte de sua demanda e dos outros municípios. 
A partir deste plano, é possível interpretar que em comparação com a disposição de empregos em sua área, Marituba não possui força de atração no que diz respeito a sistemas educacionais, em comparação com Ananindeua e Belém. Diferentemente do que foi exposto em relação aos deslocamentos por trabalho na Tabela 2, panorama este em que Marituba apresenta uma força atrativa maior.

No que diz respeito aos deslocamentos por estudo que tem Marituba como município de origem (tabela 6) e os demais do espaço metropolitano como destino, é perceptível que Belém recebe boa parte dos deslocamentos de Marituba, tendo 21,6 em IIDTE; seguido por Ananindeua com 8,4 IIDTE e Benevides com 0,8. Nessa perspectiva, Belém ainda apresenta uma grande força polarizadora nos deslocamentos por estudo, porém, em menor comparação do que sua condição em relação aos deslocamentos por trabalho, como ressaltado na Tabela 1.

\begin{tabular}{|c|c|c|c|c|c|c|c|}
\hline \multirow[t]{3}{*}{ ORIGEM } & \multirow{3}{*}{$\begin{array}{l}\text { POPUL. } \\
\text { MUNIC. } \\
\text { ORIGEM }\end{array}$} & \multicolumn{6}{|c|}{ DESTINO } \\
\hline & & \multicolumn{2}{|c|}{ Belém } & \multicolumn{2}{|c|}{ Ananindeua } & \multicolumn{2}{|l|}{ Benevides } \\
\hline & & $\begin{array}{c}\text { N. DE } \\
\text { PESSOAS }\end{array}$ & IIDTE* & $\begin{array}{c}\text { N. DE } \\
\text { PESSOAS }\end{array}$ & IIDTE & $\begin{array}{c}\text { N. DE } \\
\text { PESSOAS }\end{array}$ & IIDTE \\
\hline Marituba & 108.246 & 2235 & 21,6 & 912 & 8,4 & 87 & 0,8 \\
\hline
\end{tabular}

Tabela 6. Espaço metropolitano de Belém. Deslocamentos temporários de pessoas por motivo de estudo com origem em Marituba. 2010 Fonte: IBGE (2010); Ribeiro (2017).

* Índice de Intensidade de Deslocamento Temporário por Trabalho - determinado pela divisão do número de pessoas que realizaram o deslocamento pela população total do município em 2010, multiplicado por 1000.

Fonte: IBGE (2010); Ribeiro (2017).

É importante notar que as interações espaciais a partir dos deslocamentos de pessoas por motivo de trabalho e de estudo revelam a intensidade da conectividade dos municípios do espaço metropolitano. Enquanto é evidente a importância de Belém e Ananindeua, Marituba também apresenta papel bem relevante na emissão de pessoas que buscam empregos, além de também apresentar capacidade de atender fluxos de outros municípios. 
As interações espaciais, por si sós, já são importantes elementos na concretização da condição metropolitana, entretanto, pretende-se aqui atrelá-las a um outro vetor da metropolização, também gerador de novas interações, a promoção imobiliária, cujas características em Marituba se harmonizam fortemente com os contornos do processo de metropolização de Belém.

\section{A promoção imobiliária no âmbito da metropolização do espaço de Marituba}

A metropolização do espaço de Marituba se apresenta enquanto um processo acompanhado da dinâmica da produção imobiliária no espaço metropolitano de Belém, que ocorre a partir da atuação de dois agentes: o Estado e o promotor imobiliário privado. As políticas habitacionais vêm favorecendo o processo de metropolização de Marituba a partir do reforço dos papéis que a cidade tem no âmbito do espaço metropolitano, especialmente aqueles associados aos conteúdos sociais periféricos.

A consolidação dessa promoção imobiliária acarreta a presença de diferentes tipos de empreendimentos no espaço da cidade, como pode ser observado na figura 3.

Em Marituba, há uma presença marcante do Programa Minha Casa Minha Vida - PMCMV, com um total de 10 empreendimentos, o que corresponde ao papel que a cidade vem desempenhando no espaço metropolitano, isto é, o de espaço designado a assentar a população de baixa renda, uma vez aí havendo maior presença de terras com preços reduzidos, o que facilita para o Estado o desenvolvimento de empreendimentos dessa natureza. No entanto, também é possível constatar que há a presença de 4 empreendimentos privados, o que, por sua vez, revela a expansão de uma fronteira imobiliária de capital privado no município, acompanhando o movimento da população de alto poder aquisitivo que deseja se afastar do núcleo metropolitano.

Desses 4 empreendimentos privados de Marituba 3 são de alto padrão: Jardins Marselha, Jardins Coimbra e Miriti Internacional Golf Marina. O empreendimento Jardins das Esmeraldas obedece a uma lógica privada, no entanto, seu público alvo é popular, através da venda de lotes para construção de habitações. 


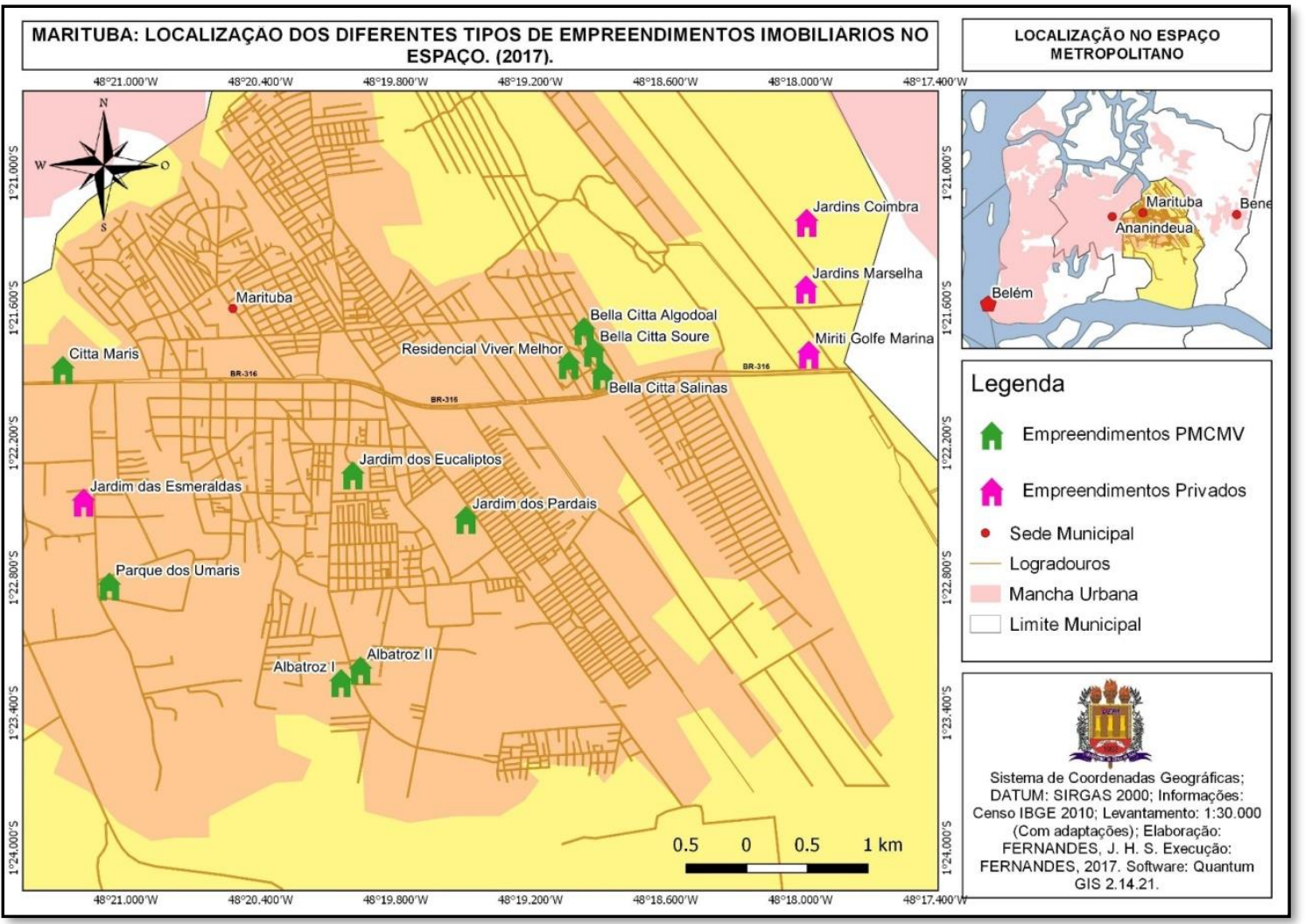

Figura 3. Marituba. Localização dos diferentes tipos de empreendimentos imobiliários. 2017. Fonte: Elaboração própria a partir de dados da base PMCMV em Marituba/Pará - Novembro 2013 e de trabalhos de campo.

A disposição desses empreendimentos no espaço de Marituba segue uma lógica diferenciada daquela que pode ser observada no PMCMV. Estes estão localizados nas extremidades da cidade (Figura 3). 0 empreendimento Jardim das Esmeraldas está próximo a saídas que se conectam a PA-483, permitindo acesso a Alça Viária; enquanto os empreendimentos Jardins Coimbra, Jardins Marselha e Miriti Internacional Golf Marina estão localizados às proximidades da rodovia BR-316.

A respeito da localização destes empreendimentos é possível compreender que ocupam posições favoráveis, tendo acesso as principais rodovias presentes em Marituba. No entanto, este fato também pode demonstrar que estes empreendimentos não estão inseridos na realidade da cidade, uma vez que, mesmo presentes no espaço maritubense, não estão próximos ao centro da cidade, especialmente os empreendimentos Miriti Golf, Jardins Marselha e Jardins Coimbra.

Essa localização afastada não necessariamente revela a intenção do promotor imobiliário ou das construtoras de opção por terrenos mais baratos, como pode ocorrer no PMCMV. Diferentemente, a disposição distante do centro da cidade torna-se um fator "positivo" para os empreendimentos, pois 
mesmo morando em Marituba, os residentes tendem a buscar serviços no núcleo metropolitano. Assim, o surgimento desses condomínios em Marituba reflete a procura da população de alto poder aquisitivo por morar em locais afastados de Belém. No entanto, por mais que se busque o afastamento, ainda há a necessidade de recorrer ao núcleo metropolitano para acessar serviços.

Com relação aos empreendimentos do PMCMV em Marituba, constatou-se um total de 10 empreendimentos, como pode ser constatado no Quadro 1, os quais se apresentam enquanto fundamentais para a organização espacial da cidade e ratificam o seu papel no espaço metropolitano por meio do mercado imobiliário.

\begin{tabular}{|c|c|c|c|}
\hline Empreendimento & N. De Habitações & Faixa & Localização \\
\hline Albatroz I & 240 & \multirow{6}{*}{ Faixa 1} & Bairro Santa Lucia II \\
\hline Albatroz II & 142 & & Bairro Santa Lucia II \\
\hline Jardim dos Eucaliptos & 256 & & Bairro Mirizal \\
\hline $\begin{array}{c}\text { Residencial Viver Melhor I, } \\
\text { II e III }\end{array}$ & 4.000 & & Bairro Parque Verde \\
\hline Jardim dos Pardais & 420 & & Bairro Decouvile \\
\hline Parque dos Umaris & 749 & & Bairro São João \\
\hline Residencial Citta Maris & 740 & \multirow[b]{2}{*}{ Faixa 2} & Bairro do Uriboca \\
\hline $\begin{array}{c}\text { Total Ville Bella Citta - } \\
\text { Condomínio Soure }\end{array}$ & 320 & & Bairro Parque Verde \\
\hline $\begin{array}{l}\text { Total Ville Bella Citta - } \\
\text { Condominio Salinas } \\
\text { Mód. I, II \& III }\end{array}$ & 496 & \multirow[t]{2}{*}{ Faixa 3} & Bairro Parque Verde \\
\hline $\begin{array}{c}\text { Total Ville Bella Citta - } \\
\text { Condominio Algodoal }\end{array}$ & 640 & & Bairro Parque Verde \\
\hline
\end{tabular}

Quadro 1. Marituba. Empreendimentos do 'Programa Minha Casa Minha Vida'. 2017 Fonte: Elaboração própria a partir dos dados do PMCMV em Marituba/PA. Novembro, 2013.

Como destacado no quadro 1, nos 10 empreendimentos localizados em Marituba há um total de 8.403 unidades habitacionais, das quais a maioria é de empreendimentos de Faixa 1, representada por 6 dos 10 residenciais, um total de 5.807 unidades habitacionais. Portanto, é possível destacar de imediato que grande parte dos contemplados pelas moradias do PMCMV em Marituba diz respeito a indivíduos com renda de 1 a 3 salários mínimos.

Essa realidade ilustra bem o caráter da promoção imobiliária em Marituba. Como destacado por Veloso (2017), o perfil do mercado imobiliário nesses munícipios do eixo Belém-Benevides é, em primeiro lugar, 
periférico, imerso no processo de dispersão metropolitana de Belém (TRINDADE JÚNIOR, 2016), marcado pelo deslocamento de população pobre do núcleo metropolitano para espaços distantes, entre os quais está Marituba.

Para assimilar como a produção dessas habitações contribui para a forma espacial de Marituba, a distribuição dos empreendimentos é um fator relevante, uma vez que os de Faixa 1 situam-se distantes do centro comercial da cidade, não obstante contam com mais linhas de ônibus a sua disposição, embora estejam mais afastados da BR-316, principal eixo rodoviário que corta a cidade - com exceção do Residencial Viver Melhor.

A localização dos empreendimentos do Faixa 1 é compreendida a partir da necessidade de se buscar áreas afastadas da rodovia BR-316 (uma localização valorizada pelo papel da via enquanto principal eixo articulador dos municípios do espaço metropolitano) como estratégia de obtenção de terrenos mais baratos. A espacialização dos empreendimentos está exposta na Figura 4.

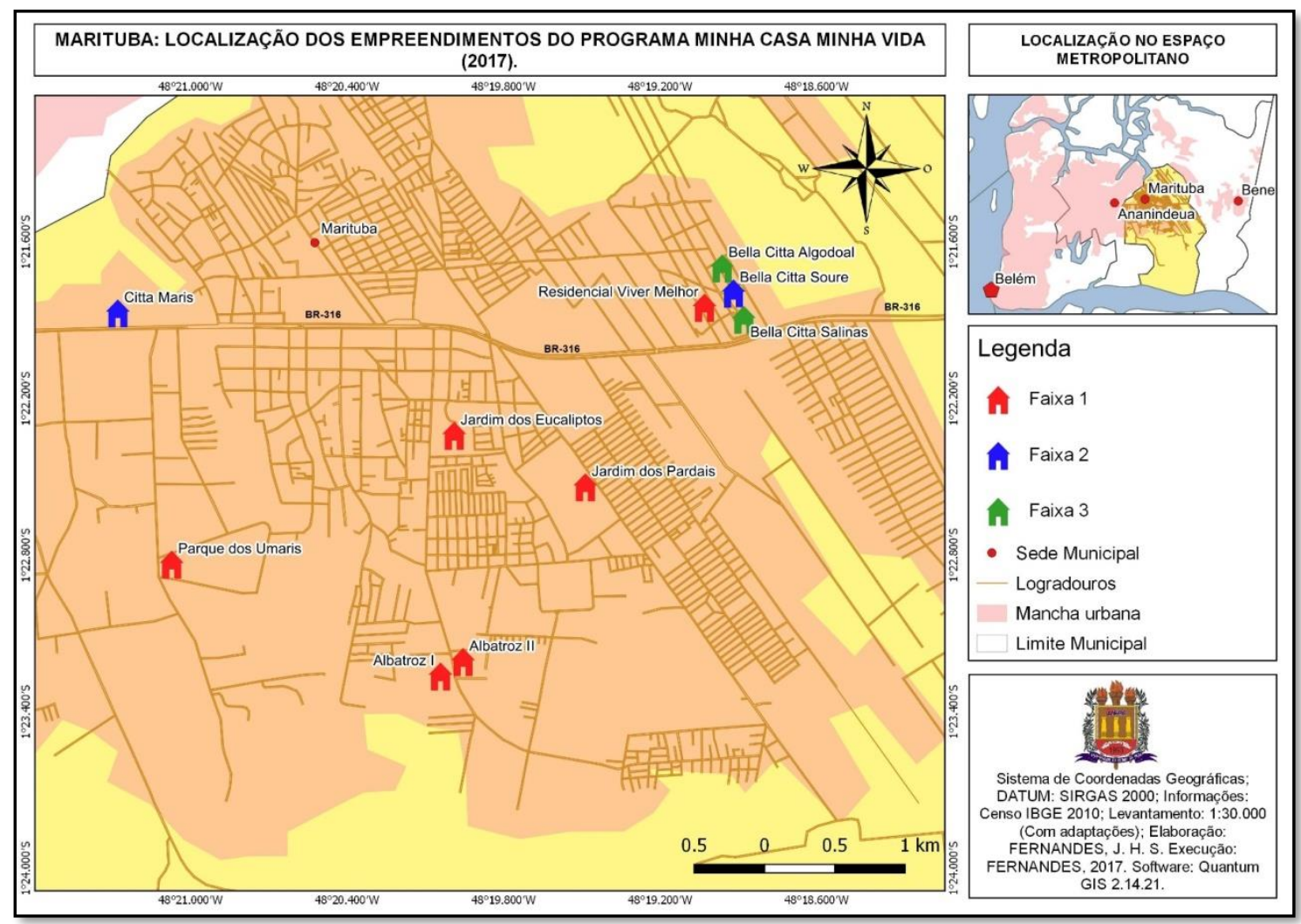

Figura 4. Marituba. Localização dos empreendimentos do PMCMV. 2017 Fonte: Elaboração própria a partir de dados da base PMCMV em Marituba/Pará - Novembro 2013. Com Adaptações. 
Ao se observar os empreendimentos de Faixa 2 e Faixa 3 já é possível constatar outro padrão de espacialização. No quadro 1, observa-se que existem 2 residenciais de Faixa 2 e outros 2 de Faixa 3. Ambas as faixas totalizam 2.596 unidades habitacionais, sendo destas, 1.060 do Faixa 2 e 1.596 da Faixa 3. A presença de habitações de faixa 2 e 3, que atingem população com renda de até 10 salários mínimos, já se mostra de menor escala em Marituba, no entanto, estas apresentam uma posição privilegiada ao longo da rodovia BR-316, o que reflete a diferenciação dessas habitações em seu perfil social e como as mesmas são contempladas pelo poder público e pelas estratégias do mercado imobiliário, em relação aos empreendimentos da Faixa 1.

A espacialização dos empreendimentos de faixa 3 em muito se assemelha aos empreendimentos privados que existem na cidade. Eles possuem essa posição privilegiada ao longo da rodovia e distante do centro, porém, devido à localização, estes apresentam diferenças quanto ao acesso de serviços de transporte. 0 Residencial Citta Maris, por estar localizado no sentido Belém-Benevides, antes do centro de Marituba, tem acesso às rotas de transporte coletivo da cidade de Marituba e Benevides, o que vem a ser uma posição privilegiada.

No entanto, os condomínios Bella Citta Salinas, Bella Citta Soure e Bella Citta Algodoal não contam com as linhas de ônibus de Marituba. Aqueles que não possuem veículo próprio precisam esperar transporte público que venha de Benevides ou de outros municípios da Região Metropolitana de Belém, a fim de se deslocarem para o centro da cidade ou do núcleo metropolitano.

Outro aspecto que merece destaque é a proximidade entre os empreendimentos Residencial Viver Melhor, Bella Citta Salinas, Bella Citta Soure e Bella Citta Algodoal. Esta localização compartilhada é oportunizada pelo plano de desenvolver um bairro apenas de empreendimentos do PMCMV, com a efetivação de serviços próximos aos condomínios para atender as necessidades dos moradores locais, com a disposição de uma Unidade de Pronto Atendimento - UPA, creches, escola e mercado local, infraestruturas necessárias diante da distância desses empreendimentos em relação ao centro de Marituba, oportunizando acesso a comércio e serviços que atenderão a 5.460 unidades habitacionais presentes no local. 
Após analisar a espacialização desses diferentes tipos de empreendimentos imobiliários em Marituba, é ratificada a tese aqui defendida de que a promoção imobiliária, através da figura do Estado e dos promotores imobiliários privados, vem compactuando com o processo de metropolização do espaço na cidade. Sendo este um aspecto do próprio processo de metropolização que ocorreu em Belém, com o deslocamento da população de baixa renda e de segmentos mais baixos da média renda, especialmente, para Marituba, propiciando o desenvolvimento da metropolização de seu espaço, dando origem a novos fluxos que passam a se desenvolver a partir de Marituba com os outros entes do espaço metropolitano de Belém.

No entanto, para atender aos objetivos desta pesquisa foi desenvolvida uma pesquisa de campo em um dos empreendimentos do PMCMV, o "Total Ville Bella Cittá - Condomínio Algodoal”, buscando compreender mais especificamente como se apresenta a realidade desses empreendimentos no espaço de Marituba e a forma como os seus residentes se inserem no quadro das interações espaciais do espaço metropolitano de Belém

\section{O empreendimento “Total Ville Bella Citta - Condomínio Algodoal” em Marituba}

O Total Ville Bella Citta - Condomínio Algodoal consiste em empreendimento da Faixa 3 do PMCMV, localizado na Av. Boulevard das Águas. (Figuras 4 e 6). Foram realizadas 20 entrevistas no local em novembro de 2017, contando, cada uma delas, com um total de 12 questões semiestruturadas, aplicadas somente aos moradores do condomínio. A opção pelo condomínio surgiu a partir de conhecimento prévio da localidade e também de inquietações sobre a distância do mesmo em relação ao centro de Marituba, bem como sobre a forma como os moradores se organizavam e obtinham os serviços dos quais necessitavam.

A figura 5 mostra o perfil do empreendimento Bella Citta - Algodoal, o último localizado na Av. Boulevard das Águas, que apresenta uma infraestrutura contrastante com aqueles de Faixa 1 e com traços de semelhança com relação aos condomínios de capital imobiliário privado, como exemplificam os muros e a portaria. 
Apesar disso, predominantemente, os moradores do local eram pessoas que possuíam apenas o ensino básico completo e tinham uma renda mensal que oscilava dentre 1 e 2 salários mínimos, com grande participação de autônomos e pessoas com empregos de baixa remuneração e com menor exigência de instrução.

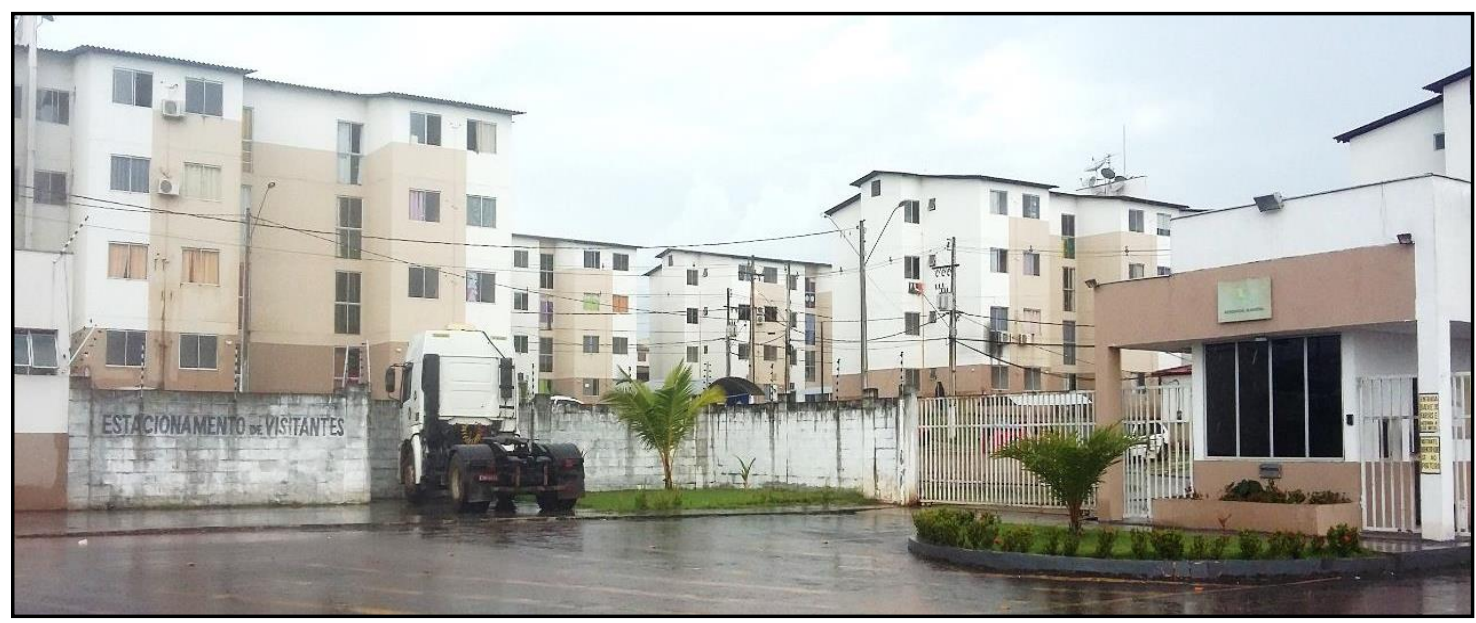

Figura 5. Marituba. Total Villa Bella Citta - Condomínio Algodoal. 2017 : Fonte:Fernandes (2017).

Dentre as várias questões abordadas nas entrevistas destaceremos aqui aquelas vinculadas mais diretamente à problemática desse artigo. Nesse sentido, os moradores foram questionados: "Você se desloca de Marituba em direção a Belém em busca de serviços?”. Dentre as respostas obtidas dos 20 entrevistados, 15 disseram se deslocar a Belém em busca de serviços que não encontravam suficientemente em Marituba. A principal motivação citada para os deslocamentos foi o trabalho, como pode ser constatado no gráfico 1

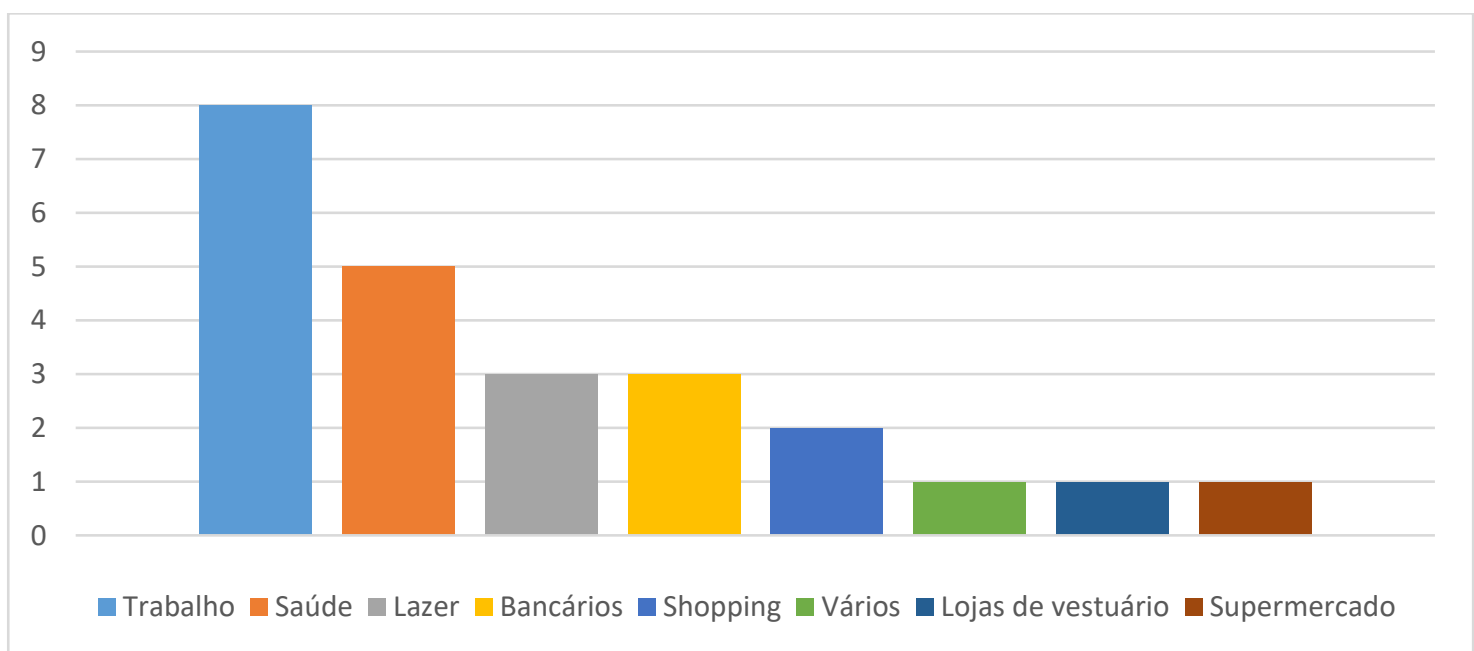

Gráfico 1. Marituba. Motivações dos deslocamentos para Belém. 2017: Fonte: Elaboração própria a partir de trabalho de campo. Total Villa Bella Citta - Algodoal, em Marituba. Novembro de 2017. 
A razão para o trabalho ser o motivo mais citado pelos entrevistados, muitas vezes, resultava do fato de que antes de morar no condomínio eles já possuíam vínculo empregatício em Belém e assim continuaram ainda que tivessem se mudado para Marituba.

Com relação ao segundo principal motivo para os deslocamentos em direção à Belém, os serviços de saúde, vários entrevistados atrelaram o fato aos planos de saúde que, segundo eles, oferecem atendimentos quase que exclusivamente em Belém. Em geral, os serviços de saúde de Marituba foram considerados pelos entrevistados como pouco diversificados e insuficientes, logo, preferiam buscar esse serviço em Belém. A fala de um dos moradores reflete bem este quadro (Informação verbal obtida em entrevista realizada em Marituba, novembro de 2017):

Sim, Acho que 100\% dos moradores do condomínio fazem isso (deslocamento). Bom, eu estudo para Belém. Questão de Lazer é só pra Belém, também, porque os shoppings ficam tudo pro centro da cidade, tudo isso. [...] A minha agência de banco fica em Marituba, mas em relação a hospital tem que ir pra Belém.

Fica evidente na fala do entrevistado que os deslocamentos para Belém são recorrentes entre os condôminos e por motivos variados. Durante as entrevistas, os moradores também foram questionados a respeito da busca de serviços em Ananindeua, por ser mais próxima e também ofertar boa variedade e densidade de serviços. Dos 20 entrevistados apenas 7 disseram se deslocar a Ananindeua, o que revelou uma importância reduzida de Ananindeua frente a Belém na oferta de serviços, ainda que a distância seja bem menor.

Para mostrar de forma mais clara esse movimento de buscar serviços e retornar ao município de origem foi perguntado aos entrevistados "Algum dos residentes em sua casa se desloca para outro município para trabalhar ou estudar? Qual?". Dos 20 entrevistados, 15 responderam que algum ou alguns dos residentes de sua casa realizam deslocamentos para trabalhar ou estudar em outras cidades. Os munícipios citados foram Ananindeua e Belém, com forte destaque para o segundo.

Esse panorama demonstra que a metrópole de Belém possui grande destaque na oferta de serviços no espaço metropolitano, tendo como efeito um direcionamento de fluxos para o núcleo metropolitano. No caso de Marituba, os deslocamentos por trabalho e em busca de serviços reforçam a conectividade da 
cidade com o núcleo metropolitano, o que somado aos fluxos para os outros entes do espaço metropolitano, como já demonstrado, insere Marituba na realidade metropolitana a partir das interações espaciais.

\section{CONSIDERAÇÕES FINAIS}

Ao se considerar a metropolização enquanto objeto de investigação é necessário fazer referência à maneira como se apresentam os novos espaços e centralidades produzidas a partir desse processo. Uma vez que, ao passo que se dispersam os aspectos associados à própria metrópole, estes vão dando continuidade ao processo de produção de seu espaço. Um movimento que não tira a relevância do núcleo metropolitano, mas que complexifica o seu espaço, não mais ficando ele restrito aos limites da metrópole.

Durante o exposto neste trabalho foi possível constatar que o processo de metropolização de Belém ocorreu através da dispersão das camadas populares do núcleo metropolitano para a periferia da metrópole, sendo esta composta pelos municípios de Ananindeua, Marituba e Benevides. O processo ocorreu mediante a ação de dois principais agentes: Estado e promotores imobiliários, que foram responsáveis por realocar esta população, a fim de atender as demandas de uma camada da população que possuía poder aquisitivo mais elevado, tornando muitos espaços em Belém altamente valorizados e, consequentemente, excludentes.

Também foi possível compreender que não só a forma do espaço de Marituba veio sendo transformada, mas, como ressaltado anteriormente, a metropolização oportunizou a conectividade desse espaço dentro da lógica metropolitana, a partir do aumento de sua articulação com Belém e com os demais entes do espaço metropolitano.

As interações espaciais analisadas neste trabalho demonstraram a intensidade das articulações entre os municípios do espaço metropolitano, de maneira mais acentuada e frequente, o que se diferencia da conectividade dos outros municípios que fazem parte da Região Metropolitana de Belém. Revelando que a dinâmica de Belém, Ananindeua, Marituba e Benevides apresenta um maior adensamento de fluxos. 
Também foi possível observar que a promoção imobiliária está diretamente relacionada e esse processo, expressando tanto a intensificação das interações espaciais caracterizadoras da condição metropolitana quanto a natureza da metropolização de Belém, por meio da prevalência do reforço ao papel de perferia da metrópole, expresso na quantidade de empreendimentos voltados a grupos menos abastados, mesmo havendo já aspectos de complexificação desse perfil por meio de empreendimentos atrelados à suburbanização de grupos abastados.

\section{REFERÊNCIAS}

ABELEM, Auriléa Gomes. Urbanização e Remoção: Por Que e Para quem? Belém: Centro de Filosofia e Ciências Humanas/UFPA: Núcleo de Altos Estudos Amazônicos, 1989.

CATELAN, Márcio José. Heterarquia urbana: interações espaciais interescalares e cidades médias. São Paulo: Cultura Acadêmica, 2013.

CORRÊEA, Roberto Lobato. Interações espaciais. In: CASTRO, Iná Elias de;

CORRÊA, Roberto Lobato; GOMES, Paulo César da Costa. (Orgs.). Explorações geográficas. Rio de Janeiro: Bertrand Brasil, 1997.

DI MÉO, Guy. Introdução ao debate sobre a metropolização. Confins [Online], n. 4, 2008.

ÉGLER, Eugênia Gonçalves. A Zona Bragantina no Estado do Pará. Revista Brasileira de Geografia. Ano XXIII, $n^{0} 3$, 1961.

FONSECA, Maria Clara de Azevedo. Governança urbana e poder local estudo de caso: o município de Marituba. Monografia (Especialização). Universidade Federal do Pará, Núcleo de Altos Estudos Amazônicos, 2007.

IBGE. Censo Demográfico Brasileiro. Rio de Janeiro: IBGE, 2010.

LEANDRO, Leonardo Milanez de Lima; SILVA, Fábio Carlos da. A estrada de ferro de Bragança e a colonização da zona bragantina no estado do Pará. Novos Cadernos NAEA, v. 15, n. 2, 2012.

LENCIONI, Sandra. Metropolização do espaço: processos e dinâmicas. In: FERREIRA, Álvaro; RUA, João; MARAFON, Glaucio José; SILVA, Augusto César Pinheiro da (Orgs.). Metropolização do espaço: gestão territorial e relações urbanorurais. Rio de janeiro: Consequência, 2013.

NASCIMENTO, Naza Cleiss Pereira do. História da Fundação da Igreja Assembleia de Deus em Marituba (1929-1939). Faculdade Ipiranga. Belém: 2013. (Trabalho de Conclusão de Curso).

NUNES, Francinaldo Alves. A Lei de Terras e a Política de Colonização Estrangeira na Província do Pará. Tempos Históricos. Volume 16 - 2º Semestre - 2012 - p. 99 - 126 Históricos ISSN 1517-4689 (versão impressa) 1983-1463 (versão eletrônica).

PENTEADO, Antônio Rocha. 0 uso da terra na região bragantina - Pará. São Paulo: Instituto de Estudos Brasileiros / Universidade de São Paulo, 1967. 
RIBEIRO, Willame de Oliveira. Interações espaciais na rede urbana do Nordeste do Pará: particularidades regionais e diferenças de Bragança, Capanema e Castanhal. 2017. Tese (Doutorado em Geografia) - Faculdade de Ciências e Tecnologia, Universidade Estadual Paulista (FCT/UNESP), campus de Presidente Prudente.

RIBEIRO, Luiz Cesar de Queiroz (Org.). Hierarquização e identificação dos espaços urbanos. Rio de Janeiro: Letra Capital/Observatório das Metrópoles, 2009.

TRINDADE JÚNIOR, Saint-Clair Cordeiro da. Formação metropolitana de Belém (1960-1997). 1. ed. - Belém, PA: Paka-Tatu, 2016.

ULLMAN, Edward Louis. Geography as Spatial Interaction. Seatle and London: University of Washington Press, 1980.

VELOSO, Tiago. Metropolização e diferenciações regionais: estruturas intraurbanas e dinâmicas metropolitanas em Belém e Manaus. Cad. Metrop., São Paulo, v. 19, n. 40, pp. 865-890, set/dez 2017. 